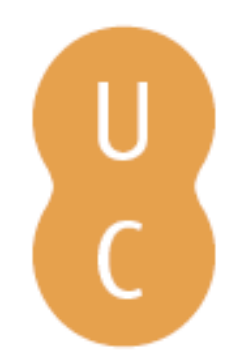

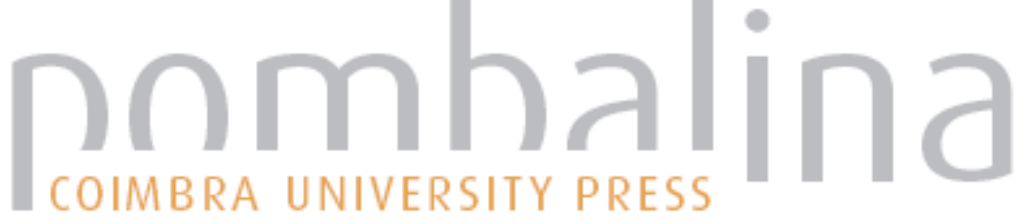

\section{Inês de Castro em invenção}
Autor(es): $\quad$ Santos, Maria Manuela
Publicado por: Imprensa da Universidade de Coimbra
URL persistente:
URI:http://hdl.handle.net/10316.2/38704
DOI:
DOI:http://dx.doi.org/10.14195/978-989-26-1164-8_27
Accessed : $\quad$ 26-Apr-2023 15:03:35

A navegação consulta e descarregamento dos títulos inseridos nas Bibliotecas Digitais UC Digitalis, UC Pombalina e UC Impactum, pressupõem a aceitação plena e sem reservas dos Termos e Condições de Uso destas Bibliotecas Digitais, disponíveis em https://digitalis.uc.pt/pt-pt/termos.

Conforme exposto nos referidos Termos e Condições de Uso, o descarregamento de títulos de acesso restrito requer uma licença válida de autorização devendo o utilizador aceder ao(s) documento(s) a partir de um endereço de IP da instituição detentora da supramencionada licença.

Ao utilizador é apenas permitido o descarregamento para uso pessoal, pelo que o emprego do(s) título(s) descarregado(s) para outro fim, designadamente comercial, carece de autorização do respetivo autor ou editor da obra.

Na medida em que todas as obras da UC Digitalis se encontram protegidas pelo Código do Direito de Autor e Direitos Conexos e demais legislação aplicável, toda a cópia, parcial ou total, deste documento, nos casos em que é legalmente admitida, deverá conter ou fazer-se acompanhar por este aviso.

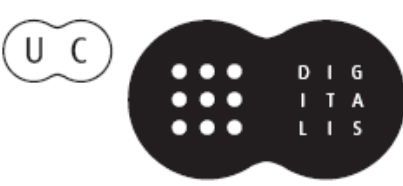


Maria Manuela Santos

Escola Secundária de Inês de Castro

\title{
INÊS DE CASTRO EM INVENÇÃO
}

\begin{abstract}
Inês de Castro, por exemplo, com ser o mais belo,
é também o mais simples assunto que ainda trataram poetas.
\end{abstract}

(Almeida Garrett, Memória ao Conservatório Real)

Construído com a leitura dentro da escrita e com a tesoura seletiva da memória, para parafrasear Compagnon, Invenção de Orfeu, de Jorge de Lima, é um texto que, inscrevendo em si vozes alheias, impossibilita o leitor de o ler em si mesmo, obrigando-o a estabelecer uma rede de conexões com outras obras que, deportadas do seu tempo e do seu lugar de origem, se não se desfiguram, dissimulando, por vezes, a sua identidade, não raro conquistam, no espaço novo, outros significados que recriam o objeto inicial, num ato de invenção.

Nasce, assim, sobre textos já existentes, uma outra mensagem, lembrando, como Genette diria, "la vieille image du palimpseste où l'on voit, sur le même parchemin, un texte se superposer à un autre qu'il ne dissimule pas tout à fait, mais qu'il laisse voir par transparence"1. Quanto a Jorge de Lima, que entende, pessoanamente, a escrita como consequência de um sopro místico inspirador, crendo que alguém lhe movimenta na sombra as mãos presas por fios secretos, antecipou o que o linguista teorizara:

1 Genette, Gérard, Palimpsestes, Paris, Éditions du Seuil, 1982, p. 451. 
Falara: e a sua fala palimpséstica

proveio; era abundante, nasceu sábia.

Que fazer dêsses passos, dessas vestes,

das canções que possuíam outros lábios?²

Entre as inúmeras presenças que povoam Invenção de Orfeu, assumem especial relevo Os Lusíadas de Camões, tal como assevera o alagoano em entrevista a Paulo de Castro $^{3}$. De resto, refletindo sobre a sua obra, Jorge de Lima confessa ao mesmo jornalista que "gostaria de mostrar-lhe um dos episódios de Inês de Castro" ${ }^{4}$. Manifesta, deste modo, uma postura respeitosamente reflexiva sobre o episódio camoniano bem como a atenção que lhe merece o seu próprio envolvimento reinterpretativo na obra de chegada. Esclarece, além disso, que as Ineses que desfilam, sempre sem apelido, no texto brasileiro, não são senão "de Castro". Com efeito, além de dedicar à "Que despois de ser morta foi Rainha" todo o XIX poema do canto II e todo o canto XIX, intitulado "Permanência de Inês", o alagoano consagrou-lhe ainda, entre os dez longos cantos de Invenção de Orfeu, uma dúzia de referências esparsas. Trata-se de alguns versos, quase todos inesperados e criativos, que, exigindo, tal como a obra no seu todo, uma leitura cautelosa que procure desvendar o jogo encoberto e perscrutar o que está para além das evidências, antecipam o ponto de vista do autor que não se confunde nem com a tradição nem com a memória. Feitos de palavras que se organizam de modo a não serem facilmente compreendidas, estes excertos dispersos anunciam um novo olhar sobre o tema inesiano, tal como constataremos quando nos ocuparmos dos dois textos mais longos. Logo na primeira referência, surge uma Inês plural, compósita, que integra vários seres, num ambiente de fatalidade e de tragédia que o particípio passado, que fecha a citação, antecedido do advérbio repetido, claramente censura:

2 Lima, Jorge de, Invenção de Orfeu, Rio de Janeiro, Livros de Portugal, S. A., 1952, canto X, poema VII, p. 367.

3 Lima, Jorge de, Auto-Retrato Intelectual, Obra Completa, $1^{\text {a }}$ edição, Rio de Janeiro, Editôra José Aguilar Lta, 1958, p. 93 (Entrevista de Paulo de Castro, "Encontro com Jorge de Lima", in Tribuna da Imprensa, Rio de Janeiro, 7 de junho de 1952): "No meu poema [Invenção de Orfeu] encontra relações com a obra de Camões a cada momento".

4 Id., ibidem, p. 92.

5 Camões, Luís de, Os Lusíadas, Org. de António José Saraiva, Porto, Figueirinhas, 1978, p. 176. 
(..)

Ah! As praias, as tragédias e as Ineses,

E os presságios bilingües, multilingües

E as visões tão fatais, tão desabridas. ${ }^{6}$

Sucedem-se, também, entre o eterno feminino que se desintegra em inúmeras figuras, outras Ineses:

Ó meninos, ó noites, ó sobrados,

ó sonetos vindouros, quatro andares

de rimas e azulejos, Isadoras,

Isas, Ineses, Lúcias, inda em flor. ${ }^{7}$

(...)

ou

(...)

Celidônia, Floreal, Inês, Lenora,

Violante e outras criaturas exumadas. ${ }^{8}$

Outras ainda, quando descontextualizadas, parecem mais habituais ou mais próximas da realidade da História: é a "doce Inês"9, a "térrea Inês"10; "(...) Inês (...), a defunta princesa soterrada"11.

Porém, a mais curiosa referência a Inês surge, porventura, no X poema do canto VI, num alinhamento imprevisto de versos que nos projeta num universo novo, não só semântico, mas também gramatical, todavia pleno de sentido. O eu lírico lamenta uma memória que o persegue e de que quer libertar-se, mas não sabe como. Faz, talvez por isso, uma pausa na continuidade narrativa do

\footnotetext{
6 Lima, Jorge de, Invenção de Orfeu, op. cit., canto I, poema XXVIII, p. 49.

7 Id., ibidem, canto VIII, poema único, p. 344.

8 Id., ibidem, canto VIII, poema único, p. 285.

9 Id., ibidem, canto X, poema XVI, p. 378.

${ }^{10}$ Id., ibidem, canto V, poema X, p. 208.

11 Id., ibidem, canto VIII, poema único, p. 312.
} 
poema para retomar, com força renovada, o desejo de eliminação da lembrança: inaugurada pelo volitivo querer, surge uma enumeração cujo envolvimento homogeneiza o valor semântico das palavras unidas pelo sema da destruição. Assim, aos verbos recalcar e desmontar, conjugados pronominalmente, no infinitivo, sucede-se a sugestiva irregularidade do substantivo libido, flexionado, seguido de dois pontos. Quebra-se, deste modo, a sequência da apresentação sucessiva dos vários elementos e aparece, no verso subsequente, um inusitado esclarecimento ou uma síntese inesperada dos versos anteriores: através de dois substantivos, também conjugados, o eu lírico propõe-se liquidar a tal memória, inesando- $a$ e lenorando- $a$. Tendo em consideração que Inês tinha entrado no tempo suspenso pela mão gelada da morte implacável e que o frio endurecia a Lenora ${ }^{12}$ o coração quieto, compreende-se, pois, que os nomes verbalizados se impõem significativos, abreviando, mas sublinhando, com vigor, a ambição inalterável do sujeito poético: a anulação da lembrança.

\author{
Nessa derrota entre mouros, \\ mora em mim essa memória \\ corporizada e constante \\ de coisa que eu não defino \\ e nem sei como extingui-la. \\ Mas nessa estrada de mar \\ quero mesmo recalcá-la, \\ desmontá-la e libidá-la: \\ inesá-la, lenorá-la. ${ }^{13}$ \\ (...)
}

12 Lenora é um nome feminino várias vezes repetido ao longo de Invenção de Orfeu, provavelmente inspirado em Edgar Allan Poe. Com efeito, o autor norte-americano, para além de ter escrito um poema justamente intitulado "Lenore", em que o eu lírico lamenta a morte prematura da personagem, assina também um outro, intitulado "The Raven”, em que o sujeito poético sofre com o desaparecimento da amada, com o mesmo nome. Traduzido para francês, por Baudelaire e por Mallarmé, este último poema suscitou, do mesmo modo, várias versões para português, sendo as mais relevantes a de Machado de Assis e a de Fernando Pessoa. Habilitado em vários idiomas, designadamente em inglês e em francês, confesso admirador de Baudelaire e de Pessoa, não surpreende, pois, que Jorge de Lima se tivesse também apaixonado por Lenora e pelas suas histórias. Cf. textos referidos em Allan Poe, Edgar, Selected Writings, England, Penguin Books, 1974, pp. 75 e 77.

13 Lima, Jorge de, op. cit., canto VI, poema X, pp. 237-238. 
Os fragmentos textuais, que disseminados ao longo da obra se vêm comentando, são lembranças súbitas do Poeta que, de vez em quando, evoca Inês, perseguindo o sonho de a ter inteira no seu livro, negligenciando, todavia, boa parte do eixo central do episódio conhecido. Silenciando os aspetos aparentemente mais estimulantes da história, Lima recria-a, tranquila, sem ódios, nem ameaças, nem vinganças, nem sangue. Procura Inês "nas faces das Ineses naturais", rejeitando, assim, o que de trágico a singulariza e aniquila ${ }^{14}$ e ela surge numa pintura bucólica e suave, propondo-se viver eternamente "contra as forças adversas", sem perder o eco longínquo do tempo mítico que a cristaliza na infância inocente. A santidade fecha a estrofe. Inconformada com a sorte agreste da terra e sabendo que o corpo é frágil, Inês espiritualiza-se, privilegiando o conforto meditativo e atento de quem ampara e preserva:
Inventar uma Inês e procurá-la
nas faces das Ineses naturais.
Ó dura imposição dessa Inês posta
em sossêgo infantil entre salgueiros
e recomposta e para sempre viva
contra as fôrças adversas, sempre santa ${ }^{15}$.

Com efeito, raras vezes a Arte, que retém genericamente do mito a história do amor trágico e da morte assassina, nos mostra a personagem sem arrepios nem soluços no peito. O que supostamente incentiva é, na verdade, como observou José Filgueira, recorrendo a Costa Pimpão, "Inês suplicante, de joelhos, de mãos postas, implorando a clemência do Rei; e os filhos esmagados de medo contra o seio materno, sob o pressentimento da fatalidade que sobre eles ia cair com mão brutal"16. Não é que Inês não tenha procurado transformar em perdão a sentença irrevogável. Mas nada resta deste combate que não conduz ao triunfo.

14 Tal como refere Fátima Marinho a propósito das "Trovas que Garcia de Resende fez à morte de Dona Ynes de Castro", "se não tivesse sido executada naquelas circunstâncias, nada a distinguiria, com efeito, de dezenas de outras amantes reais". Marinho, Fátima, "Inês de Castro - Outra era a vez", in Revista da Faculdade de Letras do Porto, II Série, Vol. II, 1990, p. 133.

15 Lima, Jorge de, op. cit., canto VIII, poema único, p. 290.

16 Costa Pimpão, As correntes dramáticas da literatura portuguesa do século xvi; e A Evolução e o Espírito do Teatro em Portugal, ed. De O Século, $1^{\text {a }}$ série, p. 162, citado por Valverde, José Filgueira, Coimbra, Livraria Almedina, 1982, p. 241. 
Ao contrário, vence a injustiça, a vingança, o medo, o amor e a morte, sentimentos e circunstâncias que, pela sua intensidade dramática, têm encorajado as mais variadas expressões artísticas e movimentado os mais diversos criadores e críticos. A Garcia de Resende e a Ferreira de Castro, com Trovas à Morte de Inês de Castro e Tragédia de Inês de Castro, respetivamente, se ficaram a dever as primeiras produções sobre o tema que "em Camões (...) recebe a auréola que há de fazê-lo atravessar o tempo" ${ }^{17}$. Como é evidente, também em Camões se inspirou Jorge de Lima. Se ele próprio não tivesse mencionado o facto ao jornalista Paulo de Castro, a que neste estudo já se fez referência, contaríamos com Luís Busatto que, em Montagem em Invenção de Orfeu, ${ }^{18}$ sublinha os versos, as expressões e as palavras que, conduzidos pelo voo da memória, o alagoano transporta do hipotexto ao hipertexto. A saber:

Estavas linda Inês posta em repouso (IO. II, XIX)

pois de teus olhos lindos já não ouso (IO. II, XIX)

que eram tudo memórias fugidias (IO. II, XIX)

Tu, só tu, puro amor e glória crua (IO. II, XIX)

para se amar depois a morta abstrata (IO. II, XIX)

Estavas, linda Inês posta em sossego. (IO. II, XIX)

Tudo deixaste, ó amor, ó engano cego (IO. II, XIX)

Levai-me à Cítia fria, ou à Líbia ardente onde em lágrimas viva eternamente (IO. IX, I)
Estavas linda Inês posta em sossego

(Os Lusíadas III, 120)

De teus fermosos olhos nunca enxuito (Os Lusíadas III, 120)

Eram tudo memórias de alegria (Os Lusíadas III, 121)

Tu só, tu, puro amor, com força crua, (Os Lusíadas III, 119)

Que depois de ser morta foi rainha (Os Lusíadas III, 118)

Estavas, linda Inês posta em sossego. (Os Lusíadas III, 120)

Naquele engano de alma ledo e cego. (Os Lusíadas III, 120)

Na Cítia fria ou lá na Líbia ardente onde em lágrimas viva eternamente. (Os Lusíadas III, 128)

17 Lourenço, Eduardo, Inês de Castro, in Coelho, Jacinto do Prado (direção de), Dicionário de Literatura, $3^{\text {a }}$ ed., Porto, Figueirinhas, 1978, Vol. II, p. 464.

18 Busatto, Luiz, Montagem em Invenção de Orfeu, Rio de Janeiro, Âmbito Cultural Edições Ltda,1978, pp. 29, 30. 
A despeito de presentificar o texto antigo, o brasileiro transforma-o através do seu olhar, investindo no seu parecer e na sua sensibilidade artística, exercendo livremente a sua fantasia criadora. Como Genette diria, "l'hipertextualité a pour elle ce mérite spécifique de relancer constamment les oeuvres anciennes dans un nouveau circuit de sens"19. Deste modo, o alagoano vai urdindo o texto, norteado pelo seu génio fecundo que nos vai revelando um mundo novo.

Convém, portanto, reconhecer que "l'hipertextualité ajoute une dimension à un texte" ${ }^{20}$ e que "l'érudition peut enrichir la lecture" ${ }^{21}$. Assim, ainda que o substrato imutável de Os Lusíadas não atue consideravelmente no hipertexto, na medida em que não altera o conteúdo da mensagem final, Jorge de Lima não deixa de assumir a permeabilidade da sua poética, entendendo-a como um espaço ecuménico, representativo de um vasto repositório de vozes que amplia a sua conceção de mundo. O que, no entanto, se verifica é que recusa investir em reproduções servis ou fazer parte de uma manifestação coletiva, elevando a sua voz que muito raramente se confunde com as que com a dele confluem.

Como já se afirmou, ao longo deste estudo, a Inês de Castro dedica o Autor as dez estrofes que compõem todo o poema XIX do canto II bem como todo o canto IX de Invenção de Orfeu a que consagra dezoito estrofes. Trata-se de textos impenetráveis às primeiras leituras. Agrupadas por acasos insensatos, as palavras não raro se articulam sem motivo que se justifique, impedindo o leitor de encontrar soluções para a sua incomunicabilidade. Perdido em enredos que nem sempre parece dominar, o Poeta exprime um fascínio especial pela instabilidade, pelo descontínuo, pela interrupção súbita das ideias, recriando territórios desconhecidos e oníricos, universos sugestivos, porém inacessíveis. A sétima estrofe do canto XIX, entre muitas outras, constitui, do que se afirma, paradigma:

Perfeitamente posta nas entranhas, planos, colunas, ramos, perspectivas, Inês erecta, lindes sempre estranhas, as auroras de sol tremulam vivas, os cabelos de nuvens, rubras anhas

\footnotetext{
19 Genette, Gérard, op. cit., p. 453.

20 Id., ibidem, p. 223.

21 Id., ibidem, p. 223.
} 
de lãs esvoaçadas mas cativas,

como cativa a criação das côres,

apenas liberdade para as flores. ${ }^{22}$

Se é, por vezes, impossível invadir o pensamento irreal e compreender como se organizam lexemas e versos entre a sombra densa que os envolve, também não é menos verdade que se erguem focos de sentido que não escapam a uma leitura perscrutante. Uns que, por terem por base o hipotexto ou a História, estimulam um estudo de tipo relacional, outros que, por serem originais, motivam para a palavra solitária do Poeta.

Comece-se, então, pelos que transparecem no hipertexto ou pelos que a História influencia.

Em vez de "Estavas linda Inês posta em sossego"23 é "Estavas linda Inês posta em repouso" 24 o verso inaugural do primeiro longo fragmento que Jorge de Lima tributa a Inês de Castro, em Invenção de Orfeu. A paráfrase, que transforma apenas uma única unidade lexical do verso emblemático do conhecido episódio de Os Lusíadas, liberta completamente o poema do sentido tradicional. De facto, se em sossego, no contexto do épico português, Inês desfruta da frescura efémera da juventude, em repouso, no último poema do brasileiro, uma vez que a palavra inscreve o sema da morte e do sono eterno, Inês surge depois da última viagem ${ }^{25}$, a vida depois da vida, aliviada dos problemas sem resolução que deixa atrás de si. Além disso, uma vez que leva consigo do passado a pujança das emoções inesquecíveis, não é na morte enterrada de abandono e de vazio que se encontra. Deambula, numa azáfama contínua, mutável e flutuante, no espaço ilimitado das constelações e das estrelas brilhantes, em confluência com as divindades

22 Lima, Jorge de, op. cit., canto IX, poema I, p. 350.

23 Camões, Luís de, Os Lusíadas, Org. de António José Saraiva, op. cit., p. 177.

24 Lima, Jorge de, op. cit., canto II, poema XIX, p. 120.

25 Ao estilo de Jorge de Lima, a ideia da morte de Inês é sublinhada, através da ausência de visão, na primeira estrofe:

"Estavas linda Inês posta em repouso mas aparentemente bela Inês; pois de teus olhos lindos já não ouso fitar o torvelinho que não vês". 
tutelares que regem o destino dos homens, para se transformar, também ela, num anjo protetor.

E para que não finde a eterna lida

e tudo para sempre se renove

nessa constante musa foragida;

entre Andrômedas e Órions alas move.

A sua trajetória é tão renhida,

que a multidão celícola comove.

Vai ser constelação de um mundo novo,

esperança maior de eterno povo. ${ }^{26}$

Algumas estâncias adiante, é possível ver, de novo, Inês, "posta em sossego", agora, como n’ Os Lusíadas. Quanto ao envolvimento, mantém-se tal como em Invenção: um céu aberto de conciliação e de esplendor; uma atmosfera de alegria e de calorosa fraternidade.

Estavas, linda Inês, posta em sossego

para sempre no mundo sideral;

baila tudo em redor do teu ofêgo,

tudo no atlas celeste era teu graal! ${ }^{27}$

(...)

Com a amada naquele mundo harmonioso de contentamento, é, sem acrimónia nem espírito de vingança, que Pedro ${ }^{28}$, a quem a "vida curta" ${ }^{29}$ de Inês tinha inibido a realização de sonhos e o cumprimento de promessas, frustrado declarações de amor, aceita, sem cruzar os braços, a sua partida antecipada. E ainda que a morte volte silenciosamente as costas sem deixar alternativa para o seu gesto implacável, o herdeiro de Afonso IV vence o obstáculo provisório da noite e, "aproveitando o

26 Id., ibidem, canto II, poema XIX, p. 122.

27 Id., ibidem, p. 122.

28 Convém esclarecer que Pedro é um nome nunca referido em Invenção de Orfeu.

29 Id., ibidem, p. 122. 
silêncio e o desamparo do crepúsculo matinal" ${ }^{30}$, investe no universo invisível da mulher dileta para pôr, uma vez mais, todo o seu amor ao seu serviço.

\section{(..)}

Vem alta noite um rei peninsular

amá-la em sua última guarida. ${ }^{31}$

(...)

Semelhante amor qual esse Rei houve

à dona Inês não é achado. Em vão! ${ }^{32}$

(...)

Ainda que tivesse consciência de que a sua paixão tinha sido suspensa por um crime desnecessário, é a ela que Pedro se dirige, e, depois de lhe rogar que se tranquilize e que o escute, explica-lhe, em discurso direto:

(...)

Ó dorida paixão, acalma-te e ouve:

Fui buscá-la alta noite em seu caixão.

Roubou-a à negra paz minha viuvez.

Pagens, vive de novo a sempre Inês. ${ }^{33}$

O sujeito lírico sugere, ao longo destes versos, o ato de amor que constituiu a trasladação do corpo de Inês do mosteiro de Santa Clara, em Coimbra, para os túmulos do mosteiro de Alcobaça, onde ela, coroada de rainha, alcança, ao lado do seu Rei, uma presença imperecível.

Tendo entendido, ao contrário de Camões, o fim como um espaço de libertação e de sossego, como o afago da ascensão, Jorge de Lima encara-o como um tempo infinito que nega o nada transitório da existência, desvalorizando, assim, a

\footnotetext{
30 Saraiva, António José, O Crepúsculo da Idade Média em Portugal (Partes I e II), Lisboa, Gradiva Publicações, Lda, s/d, p. 50.

31 Lima, Jorge de, op. cit. canto II, poema XIX; p. 121.

32 Id., ibidem, p. 121.

33 Id., ibidem, p. 121.
} 
efemeridade do amor terreno que contrasta com a eternidade do amor na morte, a elevação à unidade suprema.

Perspetivando-se como positivo o que era só injustiça, ódio, incompreensão e sangue, todos os sofrimentos se mitigam em Invenção de Orfeu. Deste modo, até os "horríficos algozes", "análogos" aos de Os Lusíadas, despidos do adjetivo inicial, perdem a força destrutiva e o poder armado de malignidade. Segue-se, depois, no poema, a "ambigüidade", secundada pelas antíteses que oscilam entre a bonomia e a maldade, - "... as asas divinas e as ferozes/ asas..."; “...doces vozes e atras vozes;" - deixando os detratores, conhecida a História e o hipertexto, vacilantes entre "a comovida hesitação do rei e a sobreposição das cruéis vozes do povo"34, o que lhes confere parte de humanidade totalmente ausente no hipotexto.
Trouxeram-na os análogos algozes ${ }^{35}$
diante da ambiguidade das essências, em que as asas divinas e as ferozes asas (que eram da Luz magnificências), confundem doces vozes e atras vozes; e eis que as piedosas, íntimas insciências: Levai-me à Cítia fria, ou à Líbia ardente, onde em lágrimas viva eternamente. ${ }^{36}$

Os dois últimos versos da estrofe, parafraseados do clássico português, fazem prova da memória inesgotável do alagoano bem como da sua cultura enciclopédica e possibilitam a Inês a última oportunidade de se furtar ao vazio da morte, antes de se deixar ir pela sua mão apaziguadora.

Apesar da presença efetiva de fragmentos de Os Lusíadas em Invenção de Orfeu, resultantes do respeito e da admiração que Jorge nutre pelo seu antecessor, o texto de base não existe, como se tem vindo a reiterar, para ser reproduzido.

\footnotetext{
34 Seabra Pereira, José Carlos, "Inês de Castro (Episódio de)", in Aguiar e Silva, Vítor (Coordenação), Dicionário de Luís de Camões, Lisboa, Editorial Caminho, 2011, p. 444.

35 Também este verso aproxima Invenção de Orfeu de Os Lusiadas: "Trouxeram-na os análogos algozes" / "Traziam-a os horríficos algozes". Todavia, não integra a lista das semelhanças, acima transcritas, da autoria de Luís Busatto.

36 Lima, Jorge de, op. cit., canto XIX, poema único, p. 352.
} 
Aos "matadores", ${ }^{37}$ subtraiu-se a parte da brutalidade primitiva e visceral que disfarçava, quem sabe, um insaciável desejo de ternura. Os punhais, através da voz poética, moderam o desejo de vingança e desistem da execução fria e da orfandade materna. E o Autor, audaz na criação de imagens, atenua a agressividade da arma, transformando-a no afago de um aroma:

(..)

O punhal que a feriu é doce tília. ${ }^{38}$

(...)

O objetivo da morte justifica a brandura do meio.

(...)

Pois que matar de amor bem que se mata

para se amar depois a morta abstrata. ${ }^{39}$

(..)

morta de amor, amada que se mata

para se amar depois em morta abstrata. ${ }^{40}$

(...)

em nós mortes sofridas para versos. ${ }^{41}$

(...)

Contrariamente ao que se verifica com grande parte dos autores que, ao longo dos séculos, se têm baseado no episódio da Castro, Jorge de Lima dispensa, como se tem vindo a observar, a crueldade, a dor da separação ou a glorificação póstuma. Por isso, na sua última produção, coloca Inês lá onde as estrelas luzem no céu para que ela seja vista e assim garanta uma existência eterna.

37 Camões, Luís de, op., cit., p. 181.

38 Lima, Jorge de, op. cit., canto II, poema XIX, p. 121.

39 Id., ibidem., p. 121.

40 Id., ibidem, canto XIX, poema único, p. 353.

41 Id., ibidem, p. 350. 
A mortalidade impõe-se, porque se impõe a imortalidade da Arte.

Tal como explicou na entrevista a Paulo de Castro, duplamente referida ao longo deste ensaio, "em Invenção de Orfeu o episódio de Inês de Castro representa um símbolo poético correspondente à perenidade da própria poesia. Portanto, em vez de uma Inês posta em sossego é uma Inês que se transforma a cada momento, mas conserva a sua integridade e perfeição através do tempo e do espaço”².

Esclarece em prosa o que sugere em poesia, sublinhando, entre os versos abundantes, os poucos vetores temáticos que lhes conferem a harmonia possível, ou, dito de outro modo, a escrita tece-se num ato recreativo de que o artista não se distancia, relevando, nas áreas temáticas repetidas, um único fôlego de intenções.

Os trechos que se seguem, por não estabelecerem nenhuma relação com a obra clássica, dão voz às palavras que não resultaram do modelo.

Inês é uma alma plural, que vem com o Poeta do tempo mítico da infância perdida, da zona mais remota da sua biografia feliz ${ }^{43}$.

$$
\begin{aligned}
& \text { (...) } \\
& \text { Ó multípara Inês, sutil e extrema. }{ }^{44} \\
& \text { (...) } \\
& \text { (...) } \\
& \text { com seus cabelos, ela-a-mais-de cem, }
\end{aligned}
$$

42 Lima, Jorge de, Auto-Retrato Intelectual. op. cit., p. 93.

43 Na verdade, vem da infância distante e inesquecível, marcada pela alegria dos afetos, o fascínio, prolongado, por Inês de Castro (Cf. Lima, Jorge de, Invenção de Orfeu, op. cit., canto XIX, poema único, p. 350):

"Ela fechada virgem, via-a em rio;

eu era os meus sete anos, vendo-a vejo

a própria poesia que surgiu

intemporal, poesia que antevejo,

poesia que me vê, verá, me viu,

ó mar sempre passando em que velejo

eu próprio outro marujo e outro oceano

em redor do marujo transmontano.

Meu pai te lia, ó página de insânia!

E eu o escutava, como se findasses".

44 Lima, Jorge de, op. cit., canto XIX, poema único, p. 349. 
a mais de mil, Inês amorfa e aresta,

Inês a só, mas logo sempre em festa. ${ }^{45}$

(...)

a musa aparecida de cem faces. ${ }^{46}$

Além de inscrever em si vários seres, a rainha de Pedro revela-se também, muitas vezes, ao longo dos textos, pela tensão interna e pela energia inspiradora. Interiormente agitada, vive em perpétuo movimento, metaforizando as águas do mar que mudam a cada instante que passa.

\section{(...)}

pois Inês em repouso é movimento, nada em Inês é inanimado e lento.

(...)

Não podendo em sossego Inês estar, foi preciso mudá-la, nessa lida, tão inconstante lida - mar e mar. ${ }^{47}$ (...)

Não podendo em sossego Inês estar, seus algozes mudaram-na na lida, na continuada lida, mar e mar. ${ }^{48}$ (...) (...)

Tu te refluis na vaga desse tema, eterna vaga, vaga em movimento, agitada e tranquila como o vento. ${ }^{49}$

\footnotetext{
Id., ibidem, p. 349.

46 Id, ibidem, p. 350.

47 Id., ibidem, p. 121, canto II, poema XIX, p. 121.

48 Id., ibidem, canto XIX, poema único, p. 352.

49 Id., ibidem, canto II, poema XIX, p. 123.
} 
Inês "corresponde à perenidade da própria poesia", sendo fonte eterna de apaziguamento do desassossego dos Poetas. Elevada à categoria de divindade pela terra inacessível em que habita e pelo estatuto etéreo que detém, transforma-se num sopro fecundo que facilita aos artistas o movimento da criação. "Musa" "chispa inventiva" a sua história, "tema em temas" 52 , e para resolver a indecisão das palavras que nascem temeratas no silêncio.

\section{(..)}

Como se além da página acenasses aos que postos em teus desassossegos, cegam seus olhos por teus olhos cegos. ${ }^{53}$

\section{(..)}

Mas sempre linda Inês, paz, desapêgo, porta da vida para os sem-sossêgo. ${ }^{54}$

\section{(...)}

as palavras e estrofes sobranceiras narram seus gestos por um seu poeta ultrapassando às musas derradeiras da sempre linda Inês, paz, desapego, porta da vida para os sem-sossêgo. ${ }^{55}$

Em textos marcados pela grandeza torrencial do seu imaginário, Jorge de Lima traz a Invenção de Orfeu uma nova personagem que, impermeável às influências, se propõe viver a independência da sua própria aventura. Distraída

\footnotetext{
50 Id., ibidem, canto XIX, poema único, p. 351.

51 Id., ibidem, p. 351.

52 Id., ibidem, p. 349.

53 Id., ibidem, p. 350.

54 Id., ibidem, canto II, poema XIX, p. 123.

55 Id., ibidem, canto XIX; poema único, p. 353.
} 
do tempo e do espaço, "nos dias dos mundos andarilha" acabado e parte para o lugar espiritual da morte onde encontra um novo sentido para a vida. Com efeito, é no mundo inominado em que descansa, sempre celebrada na sua imagem petrarquista de perfeição e beleza, que Inês permanece a inspiradora talentosa cuja mensagem os Poetas não se cansam de escrever.

56 Id., ibidem, p. 349. 